\title{
PREFERENCES OF CENTRAL EUROPEAN CONSUMERS IN CIRCULAR ECONOMY
}

\author{
Judit Olah ${ }^{1, \mathrm{a},{ }^{*}}$, Adriana Tiron Tudor ${ }^{2, \mathrm{~b}}$, Vadim Pashkus ${ }^{3, \mathrm{c}}$ and Genady Alpatov ${ }^{4, \mathrm{~d}}$ \\ ${ }^{1}$ Faculty of Economics and Business, University of Debrecen, 4032 Debrecen, Hungary; Department \\ of Public Management and Governance, College of Business and Economics, University of \\ Johannesburg, Johannesburg 2006, South Africa \\ ${ }^{2}$ Faculty of Economics and Business Administration, Babeș-Bolyai University, Ulica Teodora \\ Mihaliho č. 58-60, 400591 Cluj-Napoca, Romania \\ ${ }^{3}$ Faculty of Economics, Saint Petersburg State University, University embankment 7-9, 199034, Saint \\ Petersburg, Russian Federation \\ ${ }^{4}$ Faculty of Economics, Saint Petersburg State University, University embankment 7-9, 199034, Saint \\ Petersburg, Russian Federation \\ aalah.judit@econ.unideb.hu, badriana.tiron@econ.ubbcluj.ro, ${ }^{\mathrm{c}} \mathrm{v}$. pashkus@spbu.ru, ${ }^{\mathrm{d}} \mathrm{g}$. .alpatov@ $\mathrm{spbu} . \mathrm{ru}$ \\ *Corresponding author
}

Cite as: Olah, J., Tiron Tudor, A., Pashkus, V., Alpatov, G. (2021). Preferences of Central European consumers in circular economy, Ekonomicko-manazerske spektrum, 15(2), 99-110.

Available at: dx.doi.org/10.26552/ems.2021.2.99-110

Received: 2 June 2021; Received in revised form: 11 August 2021; Accepted: 3 September 2021; Available online: 30 December 2021

\begin{abstract}
:
Research background: Consumers' interest in environmental responsibility, sustainable consumption, and the circular economy is significantly increasing in all aspects of their lives. Clothing and fashion are clearly among these aspects. The fashion industry is one of the most resource-intensive and environmentally polluting industries. Circularity has been offered as a solution to this issue; however, the change must be in the attitudes of all concerned (Musova et al., 2021b). Businesses must react to this requirement for sustainable fashion, which is the reason that new circular concepts have been raised. Different generations prefer different models of circularity.

Purpose of the article: The purpose of the current study is to detect the existence of dependency between generation and the fashion industry's circular models, and to identify consumers' specific preferences.

Methods: The original consumer survey was undertaken by the authors in 2021, and involved 513 Slovak and 974 Czech consumers, who responded on their preferences in the circular economy. Pearson's chi-square test of independence was used to confirm the dependence between consumers' generation and the circular concept. The significant medium dependence of the nominal variables was confirmed by Pearson's contingency coefficient, C, and Cramer's V. The relationships between the generation categories of Central European consumers and the categories of the new circular models in the fashion industry were established through correspondence analysis.

Findings \& Value added: The findings of the study suggest that Baby boomers single out capsule wardrobes, Generation X prefers patchwork and slow fashion, while Millennials prioritise GOTS and SWAP. Finally, Generation Z favours leasing jeans, upcycling, and renting clothes.
\end{abstract}

Keywords: Central Europe, circular economy, consumers, fashion industry, sustainability 
Preferences of Central European consumers in circular economy

Authors: Judit Olah, Adriana Tiron Tudor,

Vadim Pashkus, Genady Alpatov

\section{JEL Classification: M14, Q56}

\section{Introduction}

Mirzynska et al. (2021) note that the circular economy has been perceived as a hot topic in recent years, as evidenced by the intensity of this issue in academic (Web of Science, Scopus) and public discourse (Twitter). Over the past ten years, the concepts and objectives of a circular economy have been increasingly detailed; they have become strategic issues for international, European, and national policies, and may be useful in developing a more sustainable scenario (Ciliberto et al., 2021; Hasheminasab et al., 2021). Teodor et al. (2020) report that the European Commission has adopted a package of measures to stimulate Europe's transition to a circular economy, which first involves efficient waste management and the consolidation of good practices in the field. Androniceanu et al. (2021) define a circular economy as a generic term used for an industrial economy that is created to be restorative, and in which the material cycle is of two kinds: the biological cycle, in which processes allow components to re-enter the environment without negative effects, and the technical/industrial cycle, in which components are used efficiently to produce other goods. Stankeviciene et al. (2020) observe that a circular economy is based on the synergy of economic, environmental, and social dimensions on micro, meso, and macro levels. The integration of the circular economy would facilitate a shift from a linear economy, which promotes the 'take-make-waste' industrial model, to a more effective economic system that is based on business models; the latter system replaces the 'end-of-life' concept with reducing, or reusing, recycling, and recovering materials in production/distribution and consumption processes. Manea et al. (2021) highlight the impact of the circular economy on social progress, which can substantiate the adjustment of national policies. Skvarciany et al. (2021) confirm that the circular economy promotes sustainable development and directly affects a country's sustainability, based on a study of 32 OECD countries. Siminica et al. (2020) also declare a positive impact of the circular economy.

On enterprise behaviour, Metzker and Zvarikova (2021) maintain that enterprises should integrate social, environmental, ethical, consumer, and human rights aspects into their businesses and core strategy in cooperation with stakeholders; such integration would maximise common values for owners/shareholders, other stakeholders, and society, and help identify, prevent, and mitigate the possible adverse effects of these aspects. The textile and fashion industry has experienced significant technological developments; however, it is currently being criticised for its environmental and social impacts, and for being a major contributor to waste (Wagner and Heinzel, 2020). Andronie et al. (2019) support a change to circularity and to the adoption of social responsibility, because not only can it bring benefits, but it can also create a positive image with favourable consequences for all parties involved, including industries and consumers. Musova et al. (2018) point out that the current state of the environment encourages more responsible behaviour by consumers on the market. Through their purchase behaviour, consumers contribute to the reduction of negative developments and betterment of the situation. This is the reason for the growing demand for a change to a circular economy in the fashion business (Ki et al., 2021). Vehmas et al. (2018) observe that current consumers appreciate the idea of recycling textile waste to produce new clothes. Circular products should become the new normal. Consumers demand more visible and concrete information about circular clothing, and are interested in how their behaviour has affected the environmental aspects of textile production. Ki and Ha-Brookshire (2021) describe consumers' moral responsibility to fashion companies as well as to themselves for creating circular fashion. Musova et al. (2021b) present new circular models in the fashion industry as comprising capsule wardrobes, renting clothes, 
GOTS certificate, slow fashion, leasing jeans, SWAP, patchwork, and upcycling. Horvath et al. (2021) highlight the importance of generation for the consumer behaviour of these new customers. Thus, the goal of the current study is to examine the existence of an association between consumers' generation and the fashion industry's circular model, and to identify consumers' specific preferences.

The following structure of the article is used: The introduction describes the origin and significance of the issue analysed, and the literature review. The second section describes the nature of the final sample of Slovak and Czech consumers, the methodological steps used, and the aim and key hypothesis of the study. The results section presents and discusses the core results, and compares them to those of similar studies. The conclusions section provides a short summary of the main results, discloses the weaknesses of the study, and suggests potential avenues for future research.

\section{Methodology}

The set of data (primary source) that was analysed comprised observations from a consumer electronic survey that was undertaken by the authors in the first half of 2021, and was based on Musova et al.'s (2021b) research. Purposive sampling was used: only those consumers who had used at least one of the new circular models in the fashion industry were allowed to respond. These levels of purposive sampling were set because of the desired robustness and reliability of the results, and the intention to analyse consumers with the same attributes (Singh and Masuku, 2014). The final sample contained responses from 1,487 participants (513 Slovak and 974 Czech consumers), all of whom were at least 18 years old. Sudman's (1976) suggestion of a required minimum of 100 elements for each major group or subgroup in the sample was satisfied for all the subgroups of the sample. First, in terms of gender, the sample contained 729 males and 758 females (Figure 1).

Figure 1: Gender

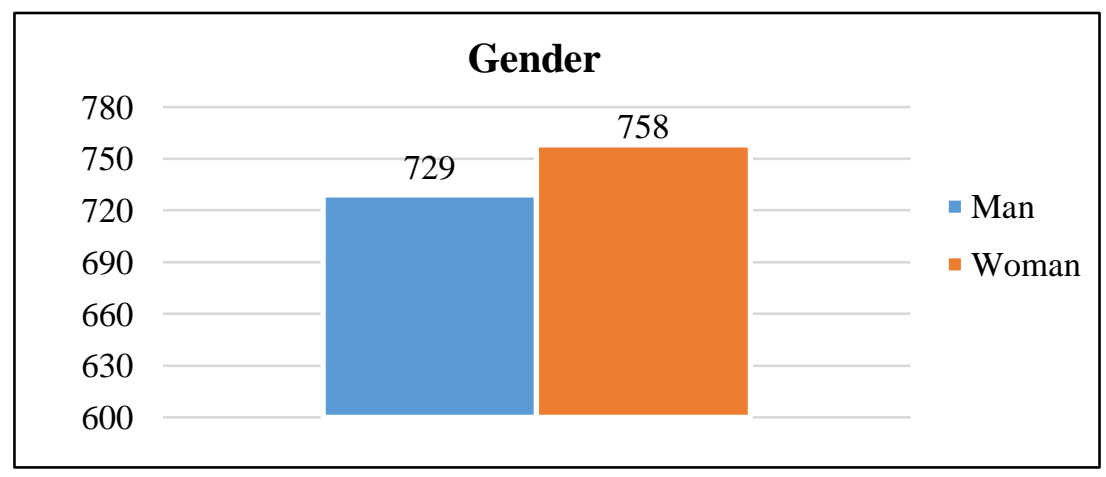

Source: own

Second, generation was analysed. The numbers for the specific generations included in the final sample are depicted in Figure 2. The respondents could choose from four categories:

1. Baby boomers (1946 - 1964),

2. Generation X (1965 - 1979),

3. Millennials $(1980-1995)$, and

4. Generation Z (1996-2009). 
Figure 2: Generation

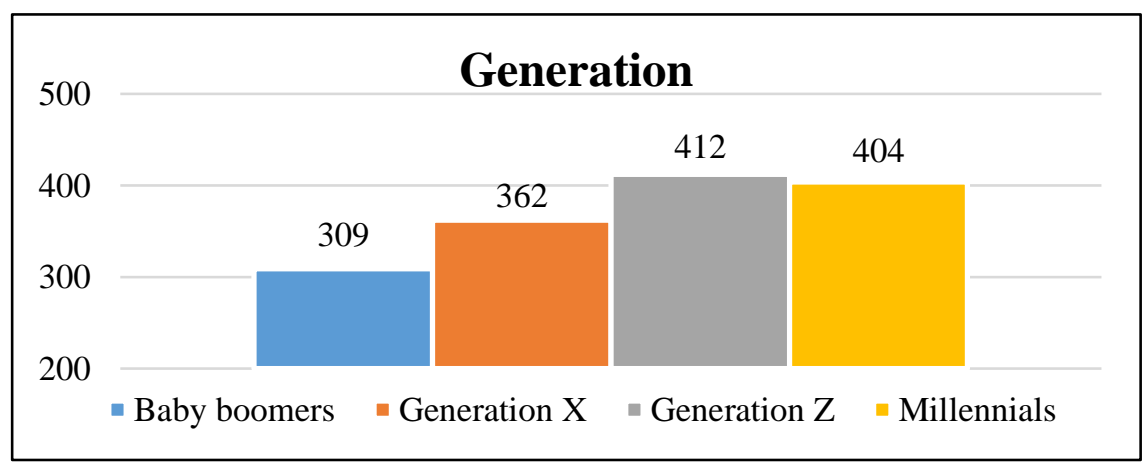

Source: own

Third, the preferred circular model was identified. The new circular concepts in the fashion industry that were included in the survey follow Musova et al. (2021b), who suggest the following new circular models: capsule wardrobes, renting clothes, GOTS certificate, slow fashion, leasing jeans, SWAP, patchwork, and upcycling. The respondents were allowed to choose only one of the models as the most preferred. The resulting numbers for the preferred circular models in the fashion industry are shown in Figure 3.

Figure 3: Circular model

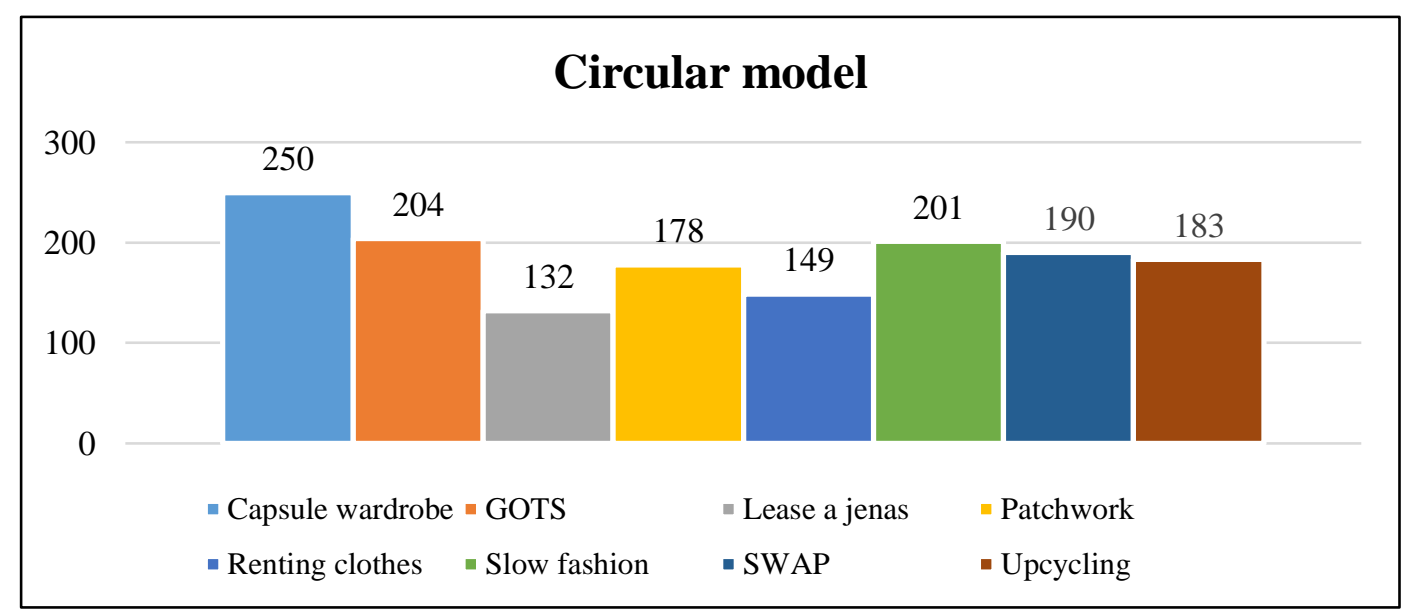

Source: own

All the tests in this study were performed at the significance level of 0.05 . The IBM SPSS Statistics v. 25 software was used, with the following methodological steps:

1. The $\chi^{2}$ test of the independence

The survey established the preferred circular model concept for the fashion industry by consumer generation from the countries analysed. A cross-tabulation of the generations of Slovak and Czech consumers and the circular models was done for the observed and expected counts. The expected counts were calculated to determine the possibility of using Pearson's $\chi^{2}$ test of independence between these nominal variables. The first assumption was that $80 \%$ of the expected observations had to be equal to or be higher than a value of 5 , while the second assumption was that all cells of the expected counts had to register frequencies higher than a value of 1 . The first part of the aim of this study is to establish the existence of a dependency between consumer generation and fashion industry circular model. The analysis allows the formulation of the main hypothesis of the study: 
$H_{0}$ : There is no significant dependence between generation and the fashion industry circular model in the Slovak and Czech consumer environment.

$H_{1}$ : There is a significant dependence between generation and the fashion industry circular model in the Slovak and Czech consumer environment.

\section{Pearson's contingency coefficient, $C$, and Cramer's $V$}

Durana et al. (2019) recommend that, where dependence is confirmed, the strength of the dependence and its statistical significance be tested by Pearson's contingency coefficient, $C$, and Cramer's $V$.

$$
C=\sqrt{\frac{\chi^{2}}{n+\chi^{2}}}
$$

where $\quad \chi^{2}$ is test statistic from Pearson's $\chi^{2}$ test and

$n$ is the number of total observations

$$
V=\sqrt{\frac{\chi^{2}}{n \cdot \min \{r-1 ; s-1\}}}
$$

where $\quad r$ is the number of rows and

$s$ is the number of columns

Valaskova et al. (2018) and Musova et al. (2021b) determine indicative limits for the intensity of the dependence (Cramer's V and Pearson's contingency coefficient) according to the following scale:

$$
\begin{array}{ll}
0.0<\text { the rate of the coefficients } \leq 0.3 & \text { weak dependence } \\
0.3<\text { the rate of the coefficients } \leq 0.8 & \text { medium dependence } \\
0.8<\text { the rate of the coefficients } \leq 1.0 & \text { strong dependence }
\end{array}
$$

\section{Correspondence analysis}

Subsequently, it is reasonable to investigate the categories of factors that are similar, if one can reject the hypothesis of the independence of the factors (Kliestik et al., 2020). Thus, a correspondence analysis was performed with an overview and a correspondence map of row points, an overview and a correspondence map of column points, and a correspondence map of row and column points, to establish the relationship between the generation categories and the circular models. This is the second part of the aim of this study: to identify consumers' specific preferences. Correspondence analysis is a method used to detect groups of similar categories. Its main advantage is the ability to analyse the relationship between the categories of two variables simultaneously. Correspondence analysis examines internal structure by means of correspondence maps that show variable categories in a reduced two-dimensional coordinate system (Durana et al., 2019; Rezankova, 2017; Kral et al., 2009). Kovacova et al. (2019) note that row and column points can be considered as coordinates of a point in $r(s)$ - dimensional space; from the viewpoint of practical application, their visual representation (projection) uses two-dimensional correspondence maps. The interpretation of a correspondence map allows the researcher to find diversity within the analysed variable profiles, as well as the co-occurrence of different categories. The $\chi^{2}$ distance was used to run the projection. Kliestik et al. (2020) highlight that projection preserves the relationship between the points of a multidimensional 
space as much as possible on two-dimensional correspondence maps. A transformation is considered appropriate if it retains the maximum proportion of the variability of multidimensional points. The variability measure is the total inertia, which is the weighted sum of the squared $\chi^{2}$ distance between each row profile and the average row profile, and is defined as follows:

$$
I^{2}=\sum_{i} p_{i+} d_{i}^{2}
$$

where

$I$ is the total inertia

$p_{i+}$ is the marginal relative frequency of Row $i$, and

$d_{i}$ is the $\chi^{2}$ distance between Row $i$ 's profile and the average row profile $d_{i}$

$$
d_{i}=\sqrt{\sum_{j} \frac{\left(p_{i j}-p_{+j}\right)^{2}}{p_{i+}}}
$$

where $\quad p_{i j}$ are relative frequencies for Row $i$ and

$p_{+j}$ is the marginal relative frequency for Column $j$.

Column categories are calculated analogically.

\section{Results}

Table 1 presents the observed (empirical) counts of the analysed nominal variables. It is a cross-tabulation of the generations and the circular models. Slovak and Czech consumers were divided according to generation and preferred new concept in the fashion industry.

Table 1: Observed counts

\begin{tabular}{llllllllll}
\hline \multirow{2}{*}{ Generation } & $\begin{array}{l}\text { Capsule } \\
\text { wardrobe }\end{array}$ & GOTS & $\begin{array}{l}\text { Lease } \\
\text { jeans }\end{array}$ & Patchwork & $\begin{array}{l}\text { Renting } \\
\text { clothes }\end{array}$ & $\begin{array}{l}\text { Slow } \\
\text { fashion }\end{array}$ & SWAP & Upcycling Total \\
\hline Baby boomers & 98 & 25 & 4 & 89 & 3 & 37 & 20 & 33 & 309 \\
Generation X & 100 & 49 & 7 & 42 & 12 & 94 & 41 & 17 & 362 \\
Generation Z & 29 & 42 & 84 & 8 & 82 & 40 & 35 & 92 & 412 \\
Millennials & 23 & 88 & 37 & 39 & 52 & 30 & 94 & 41 & 404 \\
Total & 250 & 204 & 132 & 178 & 149 & 201 & 190 & 183 & 1487 \\
\hline
\end{tabular}

Source: own

Table 2 presents a cross-tabulation of the expected counts of the variables analysed, the generations, and the fashion industry circular models. The assumptions were satisfied: of the expected observations, $80 \%$ were equal to / higher than 5 , and all the cells of the expected counts registered values greater than 1 . It was possible to perform the $\chi^{2}$ test of independence.

\begin{tabular}{|c|c|c|c|c|c|c|c|c|c|}
\hline \multirow[b]{2}{*}{ Generation } & \multicolumn{7}{|c|}{ Circular model } & \multirow[b]{2}{*}{ Upcycling } & \multirow[b]{2}{*}{ Total } \\
\hline & $\begin{array}{l}\text { Capsule } \\
\text { wardrobe }\end{array}$ & GOTS & $\begin{array}{l}\text { Lease } \\
\text { jeans }\end{array}$ & Patchwork & $\begin{array}{l}\text { Renting } \\
\text { clothes }\end{array}$ & $\begin{array}{l}\text { Slow } \\
\text { fashion }\end{array}$ & SWAP & & \\
\hline Baby boomers & 52.0 & 42.4 & 27.4 & 37.0 & 31.0 & 41.8 & 39.5 & 38.0 & 309 \\
\hline Generation X & 60.9 & 49.7 & 32.1 & 43.3 & 36.3 & 48.9 & 46.3 & 44.6 & 362 \\
\hline Generation Z & 69.3 & 56.5 & 36.6 & 49.3 & 41.3 & 55.7 & 52.6 & 50.7 & 412 \\
\hline Millennials & 67.9 & 55.4 & 35.9 & 48.4 & 40.5 & 54.6 & 51.6 & 49.7 & 404 \\
\hline Total & 250 & 204 & 132 & 178 & 149 & 201 & 190 & 183 & 1487 \\
\hline
\end{tabular}

Table 2: Expected counts

Source: own 
Thus, the core hypothesis of the study could be tested as follows:

$H_{0}$ : There is no significant dependence between generation and the fashion industry circular model in the Slovak and Czech consumer environment.

$H_{1}$ : There is a significant dependence between generation and the fashion industry circular model in the Slovak and Czech consumer environment.

Table 3: The $\chi^{2}$ test of independence

Source: own

\begin{tabular}{llll}
\hline Test statistic $\boldsymbol{\chi}^{\mathbf{2}}$ & Degree of freedom & Number of valid cases & $\boldsymbol{p}$-value \\
\hline 606.222 & 21 & 1487 & 0.000 \\
\hline
\end{tabular}

As the computed $p$-value is lower than the significance level alpha, the null hypothesis, $H_{0}$, is rejected in favour of the alternative hypothesis, $H_{1}$, based on Table 3 . There is a significant dependence between generation and the fashion industry's new circular model in the Slovak and Czech consumer environment. Having established the dependence, its strength and statistical significance can be tested.

Table 4: Cramer's V and Pearson contingency coefficient

Source: own

\begin{tabular}{llll}
\hline Nominal by nominal & Value & Number of valid cases & $\boldsymbol{p}$-value \\
\hline Pearson contingency Coefficient & 0.538 & 1487 & 0.000 \\
Cramer's V & 0.369 & 1487 & 0.000 \\
\hline
\end{tabular}

The values of Pearson's contingency coefficient, $C$, and Cramer's $V$ indicate a medium level of dependence between generation and the fashion industry's new circular model (Table 4). It is also necessary to test the significance of the resulting coefficients of contingency.

$H_{0}$ : Pearson's contingency coefficient, $C$ (Cramer's V), is not statistically significant.

$H_{1}$ : Pearson's contingency coefficient, $C$ (Cramer's V), is statistically significant.

As the computed $p$-value is lower than the significance level alpha, the null hypothesis, $H_{0}$, is rejected in favour of the alternative hypothesis, $H_{1}$, based on Table 4 . Thus, both coefficients of contingency (Pearson's contingency coefficient, $C$, and Cramer's $V$ ) are statistically significant.

Finally, correspondence analysis was performed to identify consumers' specific preferences, which meant setting the relationship between generation categories and new circular concepts: Which generation of Central European consumers prefers which circular model(s) in the fashion industry? Overviews of row and column points were computed (Tables 5 and 6). It was necessary to monitor the values in the last columns in the tables labelled, 'Total'. They represented the total inertia that assessed the quality of the created projection. The closer the value is to value 1 , the better the transformation from the multi-dimensional space into the twodimensional correspondence map. The variable, 'generation', had very good projections for Generation Z, Millennials, and Baby boomers, based on Table 5. The average quality of transformation was indicated for Generation X. The variable, 'Circular model', had the highestquality projections for GOTS, leasing jeans, and renting clothes, based on Table 6. Very good projections were made for capsule wardrobe, SWAP, upcycling, and patchwork. The purest quality of transformation of all the projections registered a value 0.375 of total inertia, which was for the circular model of slow fashion. 
Table 5: Overview of row points (Generation)

\begin{tabular}{|c|c|c|c|c|c|c|c|c|c|}
\hline \multicolumn{10}{|c|}{ Overview of row points } \\
\hline \multirow{3}{*}{ Generation } & \multicolumn{4}{|c|}{ Score in dimension } & \multicolumn{5}{|c|}{ Contribution } \\
\hline & \multirow[t]{2}{*}{ Mass } & \multirow[t]{2}{*}{1} & \multirow[t]{2}{*}{2} & \multirow[t]{2}{*}{ Inertia } & \multicolumn{2}{|c|}{$\begin{array}{l}\text { of point to inertia } \\
\text { of dimension }\end{array}$} & \multicolumn{3}{|c|}{$\begin{array}{c}\text { of dimension to inertia } \\
\text { of point }\end{array}$} \\
\hline & & & & & 1 & 2 & 1 & 2 & Total \\
\hline Baby boomers & 0.208 & -0.922 & -0.384 & 0.119 & 0.331 & 0.112 & 0.792 & 0.071 & 0.863 \\
\hline Generation X & 0.243 & -0.645 & 0.108 & 0.081 & 0.190 & 0.010 & 0.668 & 0.010 & 0.678 \\
\hline Generation Z & 0.277 & 0.884 & -0.552 & 0.139 & 0.406 & 0.307 & 0.830 & 0.167 & 0.997 \\
\hline Millennials & 0.272 & 0.381 & 0.760 & 0.068 & 0.074 & 0.571 & 0.309 & 0.634 & 0.943 \\
\hline Active total & 1.000 & & & 0.408 & 1.000 & 1.000 & & & \\
\hline
\end{tabular}

Source: own

Table 6: Overview of column points (Circular model)

\begin{tabular}{|c|c|c|c|c|c|c|c|c|c|}
\hline \multicolumn{10}{|c|}{ Overview of column points } \\
\hline \multirow{3}{*}{$\begin{array}{l}\text { Circular } \\
\text { model }\end{array}$} & \multirow{3}{*}{ Mass } & \multicolumn{2}{|c|}{ Score in dimension } & \multirow{3}{*}{ Inertia } & \multirow{2}{*}{\multicolumn{2}{|c|}{$\begin{array}{l}\text { Contribution } \\
\text { of point to inertia } \\
\text { of dimension }\end{array}$}} & \multirow{2}{*}{\multicolumn{3}{|c|}{$\begin{array}{l}\text { of dimension to inertia } \\
\text { of point }\end{array}$}} \\
\hline & & \multirow[t]{2}{*}{1} & \multirow[t]{2}{*}{2} & & & & & & \\
\hline & & & & & 1 & 2 & 1 & 2 & Total \\
\hline $\begin{array}{l}\text { Capsule } \\
\text { wardrobe }\end{array}$ & 0.168 & -0.902 & -0.369 & 0.080 & 0.256 & 0.083 & 0.912 & 0.079 & 0.991 \\
\hline GOTS & 0.137 & 0.147 & 0.702 & 0.020 & 0.006 & 0.246 & 0.079 & 0.921 & 1.000 \\
\hline Lease a jeans & 0.089 & 1.138 & -0.524 & 0.068 & 0.215 & 0.089 & 0.901 & 0.099 & 1.000 \\
\hline Patchwork & 0.120 & -0.917 & -0.090 & 0.074 & 0.189 & 0.004 & 0.730 & 0.004 & 0.734 \\
\hline Renting clothes & 0.100 & 1.028 & -0.137 & 0.057 & 0.198 & 0.007 & 0.991 & 0.009 & 1.000 \\
\hline Slow fashion & 0.135 & -0.446 & -0.060 & 0.039 & 0.050 & 0.002 & 0.372 & 0.004 & 0.375 \\
\hline SWAP & 0.128 & 0.216 & 0.935 & 0.034 & 0.011 & 0.406 & 0.093 & 0.898 & 0.991 \\
\hline Upcycling & 0.123 & 0.569 & -0.606 & 0.036 & 0.075 & 0.164 & 0.598 & 0.349 & 0.948 \\
\hline Active total & 1.000 & & & 0.408 & 1.000 & 1.000 & & & \\
\hline
\end{tabular}

Source: own

Figure 4: Correspondence maps of Generation (row points)

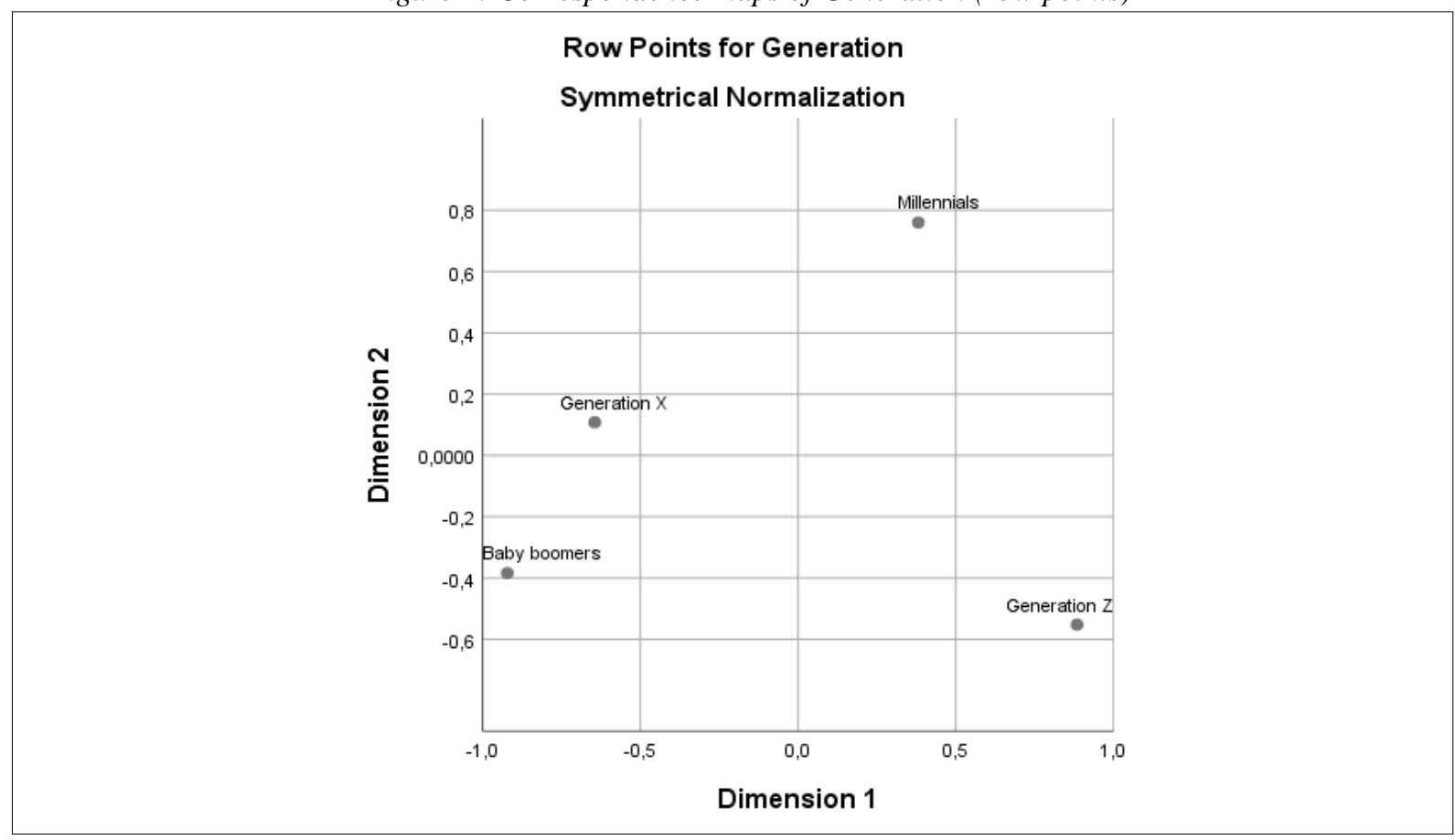

Source: own 
Figure 5: Correspondence maps of Circular model (column points)

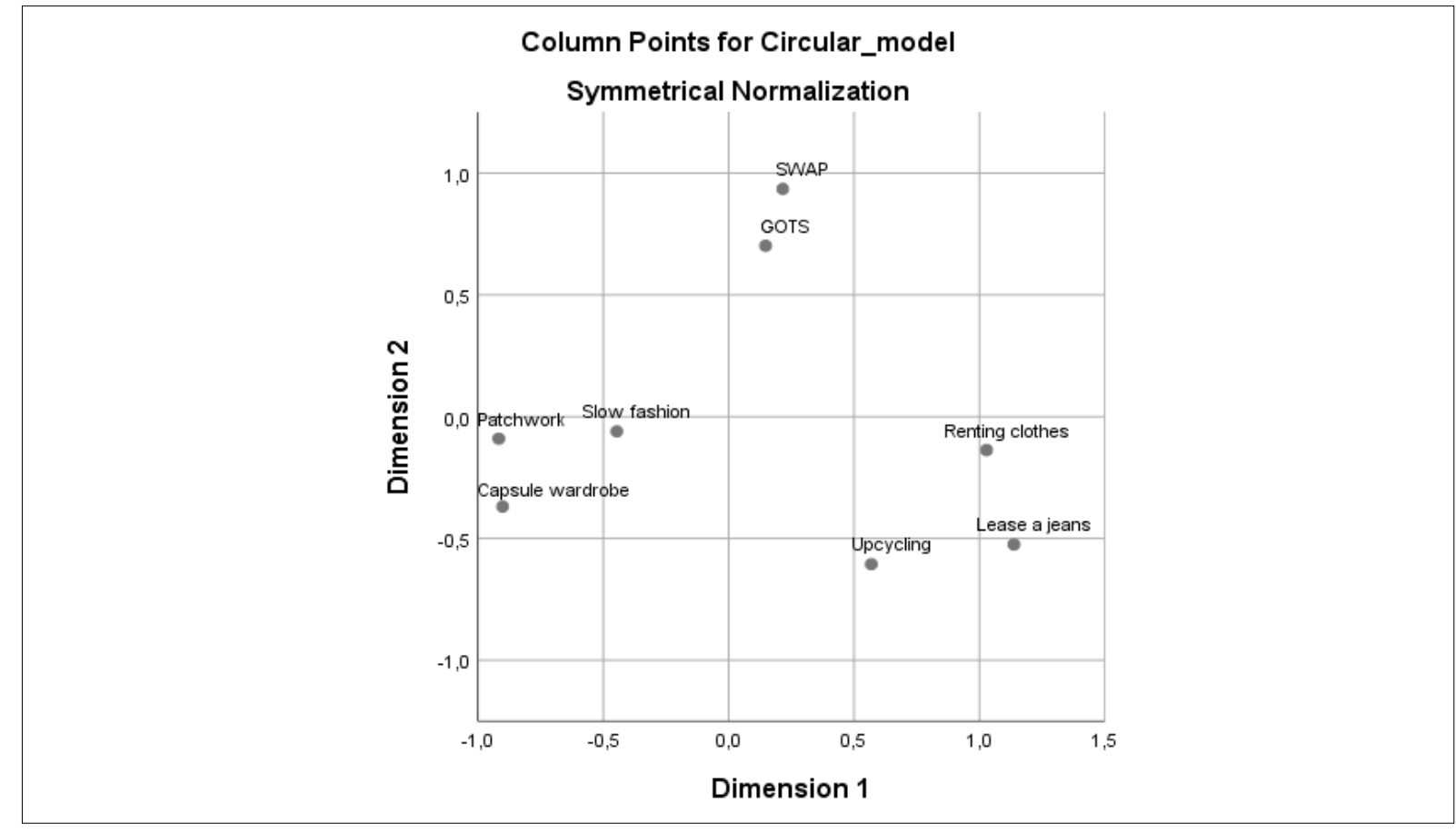

Source: own

Figure 6: Common correspondence map of Generation and Circular model

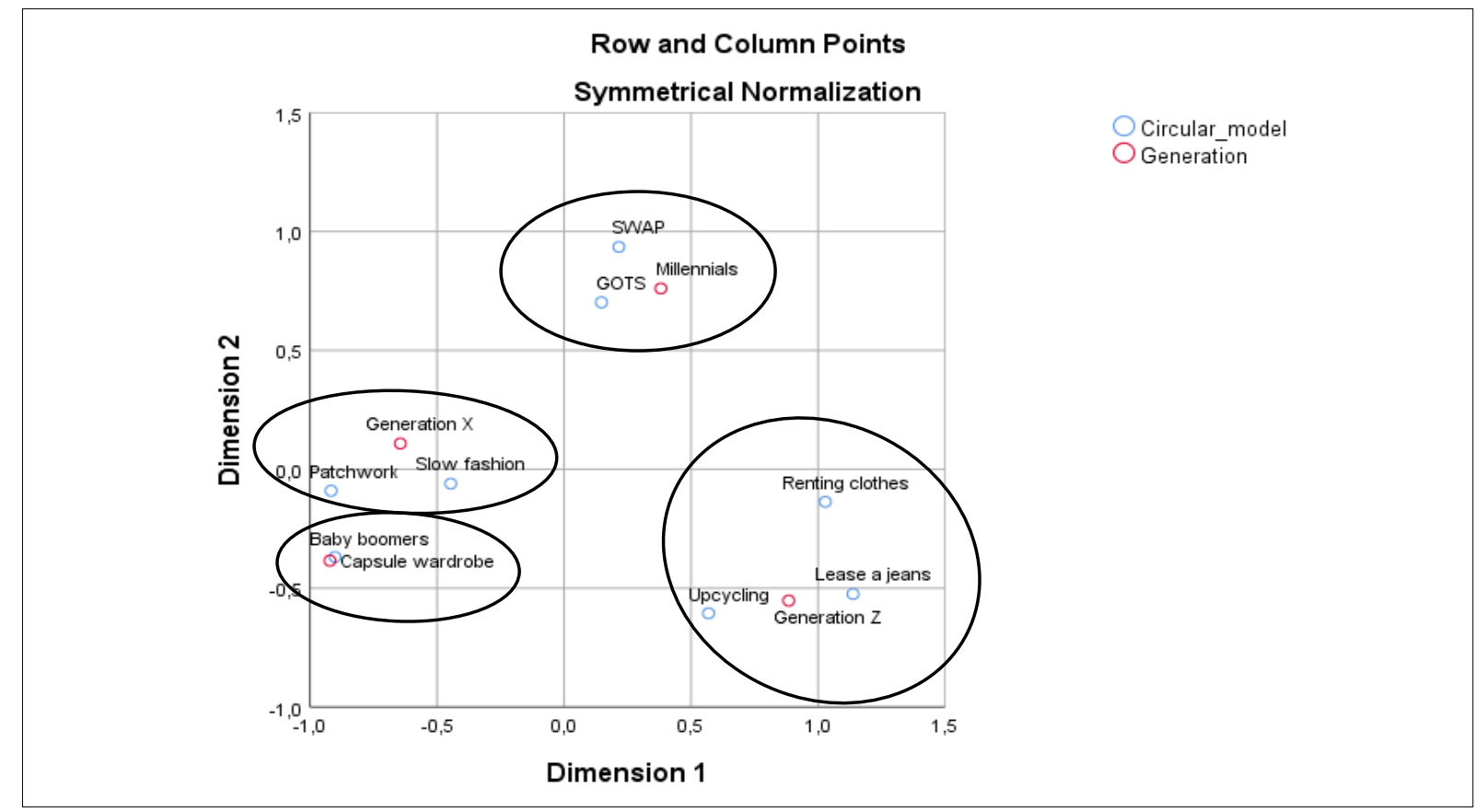

Source: own

Correspondence maps for generation and circular model were depicted in two-dimensional space according to the dimension scores in Tables 4 and 5. Figure 4 represents individual correspondence maps for generation, while Figure 5 shows individual correspondence maps for the circular model. Both maps were created based on the $\chi^{2}$ distance. 
The relationship between the categories of the variables analysed was derived based on a common correspondence map of row and column points (Figure 6). This biplot identified specific preferences for the new circular model by the generations of Slovak and Czech consumers. The following generalisations can be made, based on the sample of 1,487 Slovak and Czech respondents:

The generation of Baby boomers prefers capsule wardrobe.

1. Generation $X$ favours patchwork and slow fashion.

2. The generation of Millennials singles out GOTS and SWAP.

3. Generation $\mathrm{Z}$ prioritises leasing jeans, upcycling, and renting clothes.

\section{Discussion}

The results obtained are discussed with reference to previous studies on the topic analysed. Musova et al. (2021b) assess, using a sample of 468 Slovak respondents, the fact that the willingness to support new circular models in Slovakia is higher than the knowledge about the models in respect of all eight new circular concepts (capsule wardrobe, renting clothes, GOTS certificate, slow fashion, leasing jeans, SWAP, patchwork, and upcycling). This study analyses, individually, three models with the highest potential (slow fashion, upcycling, and patchwork) in detail. There is a statistically significant difference between the individual concepts. The willingness to support slow fashion and upcycling is found to be the same; however, there is a discrepancy in the case of upcycling and patchwork. In addition, the study confirms that there is a significant dependency between the willingness to support the three new concepts of the circular economy and the knowledge of this kind of economy. Finally, the study concludes that there is a weak dependency between the willingness to support the three models and gender, as well as between age and slow fashion. Musova et al. (2021a) analyse consumers' perception and knowledge of eco-labels and the impact on purchasing behaviour based on a sample of 434 respondents from Slovakia. They find that consumers pay adequate attention to responsible activities, which suggests positive changes in consumers' perception and approaches to environmental issues. The study notes that variables that significantly influence consumers' environmentally responsible behaviour are age, gender, income, number of household members, environmental attitudes, and knowledge of eco-labels. Ungerman and Dedkova (2021) identify sixteen tools of the circular economy in the Czech environment. According to the study, the highest rated tool was reducing energy consumption in production, waste from production, the consumption of materials, and emissions, as well as minimising waste. Their findings show that the circular economy is most used in automotive industry enterprises. Koszewska et al. (2020) compared consumers from Poland and Canada in terms of their attitudes to circular fashion. The investigation found that significant differences between the countries emerged to a greater extent in relation to the consumers' attitudes towards environmental labels for fashion products and sustainable buying behaviour. The Polish respondents perceived the need for such labels to a greater extent, whereas the Canadian ones were more willing to choose sustainable clothing and reduce consumption. The differences between the countries were much less conspicuous regarding circular cues and circularity in fashion production processes. The discrepancies appeared only in the case of clothing durability and the impact of production processes on air quality. These aspects turned out to be more important for the Polish respondents. Kovacs (2021) explores the perceptions and attitudes of the younger members of Generation Z (120 active fashion shoppers aged between 18 and 25 years) towards sustainable clothing. The findings suggest that, during their customer journey, 
young customers gather information mostly from e-commerce retailers' product descriptions, product labels, filter systems, peer-reviews, and point-of-sale communication assets found at the point of sale.

\section{Conclusions}

The objective of the study was to determine the existence of a dependency between consumers' generations and the fashion industry's circular models, and to identify consumers' specific preferences. The study focused on Slovak and Czech consumers. These close countries were chosen because of the similar attitudes and behaviour of their consumers. The results showed that there was a significant medium dependence between generation and the fashion industry's new circular models in the Central European consumer environment. It was confirmed by the $\chi^{2}$ test of independence. Based on correspondence analysis, it was found that Baby boomers singled out the capsule wardrobe. Moreover, a relationship was established between Generation X and patchwork (as well as slow fashion). Millennials prioritised GOTS and SWAP, while Generation Z favoured leasing jeans, upcycling, and renting clothes. One limitation of the study was that the sample included respondents from only Slovakia and Czechia, and not from the whole Central European region. Another limitation was the confirmation of the dependency only by the $\chi^{2}$ test of independence. The last weakness pertains to the correspondence analysis. It is only a descriptive method and does not provide an apparatus for verifying the hypotheses. Thus, the conclusions may potentially be verified by the one-sample proportion test. Therefore, future research may expand the sample to Poland and Hungary to cover all countries from the V4 region at least, and to use the Mantel-Haenszel test to confirm the dependence.

Author contributions: All authors listed have made a substantial, direct and intellectual contribution to the work, and approved it for publication.

Funding: This research received no external funding.

Data Availability Statement: Data available on request.

Conflicts of Interest: The authors declare no conflict of interest.

\section{References}

Androniceanu, A., Kinnunen, J., \& Georgescu, I. (2021). Circular economy as a strategic option to promote sustainable economic growth and effective human development. Journal of International Studies, 14(1), 6073.

Andronie, M., Simion, V. E., Gurgu, E., Dijmarescu, A., \& Dijmarescu, I. (2019). Social responsibility of firms and the impact of bio-economy in intelligent use of renewable energy source. Amfiteatru Economic, 21(52), 520-535.

Ciliberto, C., Szopik-Depczynska, K., Tarczynska-Luniewska, M., Ruggieri, A., \& Ioppolo, G. (2021). Enabling the circular economy transition: A sustainable lean manufacturing recipe for Industry 4.0. Business Strategy and the Environment, 30(7), 3255-3272.

Durana, P., Kral, P., Stehel, V., Lazaroiu, G., \& Sroka, W. (2019). Quality culture of manufacturing enterprises: A possible way to adaptation to Industry 4.0. Social Sciences, 8(4), 124.

Hasheminasab, H., Hashemkhani Zolfani, S., Kazimieras Zavadskas, E., Kharrazi, M., \& Skare, M. (2021). A circular economy model for fossil fuel sustainable decisions based on MADM techniques. Economic ResearchEkonomska Istraživanja, 1-19.

Horvath, J., Gavurova, B., Bacik, R. \& Fedorko, R. (2021). Identification of uncertainty factors in the consumer behaviour of the new generation of customers at the e-commerce level. Journal of Tourism and Services, 22(12), 168-183. 


\section{Preferences of Central European consumers in circular economy \\ Authors: Judit Olah, Adriana Tiron Tudor, Vadim Pashkus, Genady Alpatov}

Ki, C. W., \& Ha-Brookshire, J. E. (2021). Consumer versus corporate moral responsibilities for creating a circular fashion: Virtue or accountability?. Clothing and Textiles Research Journal, 0887302X20986127.

Ki, C. W., Park, S., \& Ha-Brookshire, J. E. (2021). Toward a circular economy: Understanding consumers' moral stance on corporations' and individuals' responsibilities in creating a circular fashion economy. Business Strategy and the Environment, 30(2), 1121-1135.

Kliestik, T., Valaskova, K., Lazaroiu, G., Kovacova, M., \& Vrbka, J. (2020). Remaining financially healthy and competitive: the role of financial predictors. Journal of Competitiveness, 12(1), 74-92.

Koszewska, M., Rahman, O., \& Dyczewski, B. (2020). Circular fashion-consumers'attitudes in cross-national study: Poland and Canada. Autex Research Journal, 20(3), 327-337.

Kovacova, M., Kliestik, T., Valaskova, K., Durana, P., \& Juhaszova, Z. (2019). Systematic review of variables applied in bankruptcy prediction models of Visegrad group countries. Oeconomia Copernicana, 10(4), 743772.

Kovacs, I. (2021). Perceptions and attitudes of Generation Z consumers towards sustainable clothing: Managerial implications based on a summative content analysis. Polish Journal of Management Studies, 23(1), 257-276.

Kral, P., Kanderova, M., Kascakova, A., Nedelova, G., \& Valencakova, V. (2009). Multidimensional statistical methods with a focus on solving problems of economic practice. UMB.

Manea, D. I., Istudor, N., Dinu, V., \& Paraschiv, D. M. (2021). Circular economy and innovative entrepreneurship, prerequisites for social progress. Journal of Business Economics and Management, 22(5), 1342-1359.

Metzker, Z., \& Zvarikova, K. (2021). The perception of company employees by SMEs with CSR concept implementation. International Journal of Entrepreneurial Knowledge, 9(1), 81-96.

Mirzynska, A., Kosch, O., Schieg, M., Suhajda, K., \& Szarucki, M. (2021). Exploring concomitant concepts in the discussion on the circular economy: A bibliometric analysis of Web of Science, Scopus and Twitter. Technological and Economic Development of Economy, 27(6), 1539-1562.

Musova, Z., Musa, H., \& Ludhova, L. (2018). Environmentally responsible purchasing in Slovakia. Economics \& Sociology, 11(4), 289.

Musova, Z., Musa, H., \& Matiova, V. (2021). Environmentally responsible behaviour of consumers: Evidence from Slovakia. Economics \& Sociology, 14(1), 178-198.

Musova, Z., Musa, H., Drugdova, J., Lazaroiu, G., \& Alayasa, J. (2021). Consumer attitudes towards new circular models in the fashion industry. Journal of Competitiveness, 13(3), 111-128.

Rezankova, H. (2017). Analysis of data from questionnaire surveys. Professional Publishing.

Siminica, M., Avram, M., Roxana, L. P., \& Avram, L. (2020). The adoption of national green procurement plans from the perspective of circular economy. Amfiteatru Economic, 22(53), 15-27.

Singh, A. S., \& Masuku M. B. (2014). Sampling techniques \& determination of sample size in applied statistics research: An overview. International Journal of Economics, Commerce and Management, 2(11), 1-22.

Skvarciany, V., Lapinskaite, I., \& Volskyte, G. (2021). Circular economy as assistance for sustainable development in OECD countries. Oeconomia Copernicana, 12(1), 11-34.

Stankeviciene, J., Nikanorova, M., \& Cera, G. (2020). Analysis of green economy dimension in the context of circular economy: The case of Baltic sea region. $E$ \& M Ekonomie a Management, 23(1), 4-18.

Sudman, S. (1976). Applied sampling. Academic Press.

Teodor, C., Trica, C. L., Ignat, R., \& Dracea, R. M. (2020). Good practices of efficient packaging waste management. Amfiteatru Economic, 22(55), 937-953.

Ungerman, O., \& Dedkova, J. (2021). Current implementation of the circular economy in enterprises in the Czech Republic. Review of Economic Perspectives, 21(2), 189-210.

Valaskova, K., Kliestik, T., Svabova, L., \& Adamko, P. (2018). Financial risk measurement and prediction modelling for sustainable development of business entities using regression analysis. Sustainability, 10(7), 2144.

Vehmas, K., Raudaskoski, A., Heikkila, P., Harlin, A., \& Mensonen, A. (2018). Consumer attitudes and communication in circular fashion. Journal of Fashion Marketing and Management: An International Journal, 22(3), 286-300.

Wagner, M. M., \& Heinzel, T. (2020). Human perceptions of recycled textiles and circular fashion: A systematic literature review. Sustainability, 12(24), 10599. 